\title{
Awareness, Attitudes, and Infection Control Measures of Dentists in Turkey Regarding COVID-19 Pandemic
}

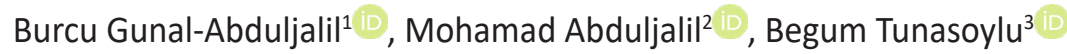 \\ ${ }^{1}$ Near East University, Faculty of Dentistry, Department of Prosthodontics, Mersin10, Turkey \\ ${ }^{2}$ Near East University, Faculty of Dentistry, Department of Endodontics, Mersin10, Turkey \\ ${ }^{3}$ Ministery of Health, General Directorate of Health Services, Ankara, Turkey \\ Correspondence Author: Burcu Günal-Abduljalil \\ E-mail: burcugunal@hotmail.com \\ Received: $16.10 .2020 \quad$ Accepted: 19.04 .2021
}

\begin{abstract}
Objective: Corona virus disease is a serious acute respiratory infection that has spread worldwide. The aim of this survey study was to evaluate the knowledge levels, attitudes, and approaches of dentists in Turkey and to investigate the infection control measures applied by the dentists in the dental clinics regarding the COVID-19 pandemic.

Methods: This survey consisted of 27 questions and was conducted in May 2020. The questionnaire, which was distributed online to the participants through their personal accounts, included questions about the socio-demographic characteristics of the participants, their knowledge and awareness of COVID-19 infection, their approach to dental procedures before and during the pandemic, and the control measures they took in dental clinics. The collected data were subjected to statistical analysis using Chi-square tests and $\mathrm{P}$ values of $<0.05$ were accepted as statistically significant.

Results: Eight hundred twenty-eight dentists completed the questionnaire forming a response rate of $51.8 \%$. The majority of the participants demonstrated a high level of knowledge and awareness regarding COVID-19. The statistical analysis showed that there was no association between the gender of dentists and the applied infection control measures $(P>0.05)$, while there were significant associations between the health sectors and experience years with the infection control measures $(P<0.05)$.

Conclusion: These results demonstrated an adequate level of knowledge regarding COVID-19 among dentists in Turkey. Additionally, the rate of using personal protective equipment during dental treatment was high.

Keywords: COVID-19, Dentist, Attitude, Infection control measures, Turkey
\end{abstract}

\section{INTRODUCTION}

The new coronavirus disease (COVID-19), which started in Wuhan, China in December 2019, has rapidly turned into a public health crisis and has spread exponentially to other parts of the world (1). On January 31, 2020, the World Health Organization (WHO) identified the COVID-19 outbreak as a universal public health emergency (2). In Turkey, the first case of the new coronavirus was confirmed by the Ministry of Health on March 10, 2020 (3). One day later (March 11, 2020), it was stated by WHO that this disease was declared as a pandemic and there were more than 118,000 cases in 114 countries and 4291 deaths (4).

The novel coronavirus belongs to the family of single-chain RNA viruses known as Coronaviridae (5). This virus family of zoonotic origin and known to be transmitted from animals to humans included diseases such as Severe Acute Respiratory Syndrome CoronaVirus (SARS-CoV), which identified in 2002, and Middle East Respiratory Syndrome CoronaVirus (MERSCoV), which identified in 2012 (6). Due to the similarity of the genome sequence of this novel coronavirus, which popularly called COVID-19, with other beta-coronaviruses such as SARS-CoV and MERS-CoV, the coronavirus working group of the International Viruses Taxonomy Committee gave the scientific name to the new coronavirus "SARS-CoV-2" (Severe Acute Respiratory Syndrome CoronaVirus 2) (7). It was stated that the transmission rate of SARS-CoV-2 is significantly higher than that of SARS-CoV and MERS-CoV $(6,8)$.

According to the WHO status report on September 12, 2020, more than 28.3 million COVID-19 cases and 911,877 deaths were reported in 216 countries around the world (9). On the same date, it was stated that there were 288,126 cases and 6,951 deaths in the Republic of Turkey (10). Despite the universal efforts to take the spread of this disease under control, the epidemic increased because of the community spread pattern of this infection (1). For this reason, identification, protection, treatment and measures are very important in order to properly stop further spread of this 
disease. Unfortunately, there have been significant changes in our professional lives due to the negative conditions created by the COVID-19 pandemic which affects all countries seriously these days. Considering the widespread contagiousness of SARS-CoV-2 and the reports of its spread to healthcare providers (11-13), dentists, who are healthcare workers too, are at high risk for hospital infection and may become potential carriers of the disease (1).

Patients infected with this viral infection, commonly accompanied by clinical symptoms such as fever, cough, and muscle pain / malaise, have abundant SARS-CoV-2 in their nasopharyngeal and salivary secretions $(14,15)$ and its transmission is thought to be predominantly by droplet and close contact to these patients (16). COVID-19 is also likely to spread when exposed to high concentrations of aerosols in a relatively closed environment $(13,17)$. During performing the dental treatments, dentists usually are close to the patient's oropharyngeal area and may use high-speed instruments that often cause aerosol formation (1). Dentists may encounter patients with suspected or confirmed COVID-19 infection and it is essential that they take this into consideration and follow a specific protocol not only to provide the dental treatment but also to prevent the spread of the infection to the clinic. Unfollowing these special precautions may expose patients to the cross-contamination in the clinic $(1,18)$.

In this challenging period, it is essential to understand the importance of the aerosol spread in the dental clinic and to take some special precautions in addition to the standard measures applied by the dentists. Temporary guidelines were provided by WHO (19), Center for Disease Control and Prevention (CDC) (20), and American Dental Association (ADA) (21) in order to prevent and control COVID-19 infection in dental treatments and to minimize the risk of infection transmission. The aim of this cross-sectional study was to understand the knowledge levels, awareness, and attitudes of dentists worked in Turkey regarding the COVID-19 pandemic, as well as to investigate the treatment approach and control measures in the dental practice before and during the pandemic.

\section{METHODS}

The present study was approved by the Scientific Research Ethics Evaluation Board with protocol number (YDU/2020/791079). Using Google Forms, a questionnaire was designed for this study which included questions about knowledge, awareness and attitudes of dentists in Turkey regarding COVID-19. This online survey was conducted in the first two weeks of May 2020 and distributed to the participants through their personal contact accounts including e-mail, WhatsApp and social media platforms (Facebook and Instagram). Each participant was randomly selected and contacted individually and all participants were registered in the Turkish Dental Association. Surveys were conducted anonymously to protect the confidentiality and privacy of all information obtained from the participants.
The questions in this survey were prepared depending on the data and guidelines provided by WHO (19), CDC (20), ADA (21), and the related literature. The questionnaire consisted of 5 parts and included 27 multiple-choice questions. In the first part of the questionnaire, participants were asked to read the consent form and confirm that they agreed to fill the questionnaire. The second part included questions related to the socio-demographic characteristics of the participants. Questions about dentists' awareness regarding COVID-19 infection and the features of the mask types, which reported by $A D A$, were included in the third part. The fourth part included questions regarding the approaches to dental procedures before and during the COVID-19 pandemic. The last part's questions were about dental treatments which applied during the pandemic and evaluating the control measures to be taken while performing dental treatments recommended by $C D C$ and ADA. These measures included the following, taking the main complaint of the patients first by phone, measuring the patient's fever and asking if there were any COVID-19 symptoms within 14 days, maintaining the social distance ( 6 feet, $2 \mathrm{~m}$ ) between the patients in the waiting room, using extraoral dental radiographs (panoramic or tomography) as an alternative, since intraoral radiographs may cause increased saliva or cough, accepting only the patients in the clinic without relatives, using protective equipment for all dental workers, disinfecting the hands before and after the dental procedure with 60-95\% alcohol, or washing them with soap-water for at least 20 seconds, rinse patients' mouths with $1.5 \%$ hydrogen peroxide or $0.2 \%$ povidone before starting the treatment, using absorbable sutures in surgical cases, avoid using aerosol-generating devices as much as possible, heat sterilizing the handpiece (if used) after each patient, and adequately ventilating the clinic after each patient.

\subsection{Statistical Analysis}

The data were statistically analyzed using IBM SPSS Statistics for Windows (version 22.0; IBM Corp., Armonk, NY). Descriptive statistics (frequencies, and percentages) were used to describe the quantitative and categorical variables. In order to determine the association between the infection control measures and independent variables including gender, occupation, specialty in dentistry, health sector, and experience years in the profession, Chi-square tests were used and $P$ values of $<0.05$ were accepted as statistically significant.

\section{RESULTS}

In total, 828 out of 1600 participants completed the questionnaire, resulting in a $51.8 \%$ response rate. Table 1 showed the profile characteristics of the dentists in this questionnaire. The answers showed that the participants were between the ages of 22-69 years in which the rate of participants under the age of 30 years was $48.8 \%$ compared to $51.2 \%$ of those aged 30 and over. Of the respondents, 
$58.9 \%$ were female and $41.1 \%$ were male. The majority of dentists $(87.2 \%)$ who completed the questionnaire were practitioners and only $12.8 \%$ of them were academics. The results showed that the respondents worked in different health sectors and the lowest percentage was for those who worked in private universities (6.8\%). Dentists in this survey had a wide range of years of professional experience.

Table 1. The characteristics of the 828 dentists enrolled in the study.

\begin{tabular}{|l|c|}
\multicolumn{1}{|c|}{ Variable } & Number (percent) \\
\hline 1. Age & \\
$<30$ & $404(48.8 \%)$ \\
$\geq 30$ & $424(51.2 \%)$ \\
\hline 2. Gender & \\
Female & $488(58.9 \%)$ \\
Male & $340(41.1 \%)$ \\
\hline 3. Occupation & \\
Dental practitioner & $722(87.2 \%)$ \\
Academician & $106(12.8 \%)$ \\
\hline 4. Specialty in dentistry & \\
General practitioner & $470(56.8 \%)$ \\
Specialist & $358(43.2 \%)$ \\
\hline 5. Health sector & \\
Private clinic & $202(24.4 \%)$ \\
Governmental university & $142(17.1 \%)$ \\
Private university & $56(6.8 \%)$ \\
Governmental hospital & $230(27.8 \%)$ \\
Private hospital & $198(23.9 \%)$ \\
\hline 6. Experience years in the profession & \\
1-5 years & $406(49 \%)$ \\
6-10 years & $246(29.7 \%)$ \\
11-15 years & $76(9.2 \%)$ \\
16-20 years & $36(4.3 \%)$ \\
$\geq 21$ years & $64(7.7 \%)$ \\
\hline 7. Have you been in the fillation team? & \\
Yes & $74(8.9 \%)$ \\
No & $574(91.1 \%)$ \\
\hline
\end{tabular}

In the third part of the questionnaire, 4 questions about the SARS-CoV-2 disease were prepared in order to investigate the participants' awareness (Table 2). All of the COVID-19 symptoms listed in Table 2 were confirmed by the CDC (22). The vast majority of participants (92\%) were aware of the main symptoms of SARS-CoV-2 (fever, cough, fatigue, and difficulty breathing). Of the respondents, $86.2 \%$ reported that the loss of taste or smell is a COVID-19 symptom, and approximately $75 \%$ of them reported symptoms such as muscle and throat aches. More than half of the dentists were also aware of other symptoms. Over $92 \%$ of the dentists correctly reported the transmission routes of SARS-CoV-2 which were, people who are in close contact, infected person coughs, sneezes or talks and touching the infected surfaces. Approximately three-quarters of the participants (73.2\%) answered the question about the incubation time of SARS-CoV-2 with 2-14 days. The high risk groups regarding COVID-19 which stated by $\operatorname{CDC}(23)$ are shown in Table 2 . The question regarding these high-risk groups were correctly answered by more than $60 \%$ of the dentists in the present survey.
Table 2. Dentists' awareness regarding SARS-CoV-2 disease and N95 masks.

\begin{tabular}{|l|c|}
\hline Variable & Number (percent) \\
\hline 1. Symptoms of COVID-19 & \\
Fever & $818(98.8 \%)$ \\
Cough & $804(97.1 \%)$ \\
Difficulty breathing & $804(97.1 \%)$ \\
Fatigue & $780(92.2 \%)$ \\
Loss of taste or smell & $714(86.2 \%)$ \\
Muscle aches & $626(75.6 \%)$ \\
Throat ache & $312(75.4 \%)$ \\
Diarrhea & $536(64.7 \%)$ \\
Nausea or vomiting & $420(50.7 \%)$ \\
Chill & $416(50.2 \%)$ \\
Congestion or runny nose & $276(57.5 \%)$ \\
Headache & $424(51.2 \%)$ \\
\hline 2. Transmission methods of CoVID-19 & \\
Between people who are in close contact & $782(94.4 \%)$ \\
Infected person coughs, sneezes or talks & $824(99.5 \%)$ \\
Touching the infected surfaces & $768(92.7 \%)$ \\
\hline 3. Incubation period & \\
2-14 days & $606(73.2 \%)$ \\
1-7 days & $12(1.4 \%)$ \\
7-14 days & $158(19.1 \%)$ \\
14-21 days & $52(6.3 \%)$ \\
\hline 4. People in high risk to get infected & \\
Older adults (more than 65 years) & $802(96.9 \%)$ \\
People with asthma & $784(94.7 \%)$ \\
People with chronic lung disease & $814(98.3 \%)$ \\
People with liver diseases & $518(62.6 \%)$ \\
People with chronic kidney disease & $676(81.6 \%)$ \\
People with diabetes & $662(80 \%)$ \\
People with severe obesity & $584(70.5 \%)$ \\
People who have serious heart conditions & $696(84.1 \%)$ \\
People who are immunocompromised & $794(95.9 \%)$ \\
People who have hemoglobin disorders & $512(61.8 \%)$ \\
\hline 5. N95 masks are available in different sizes & $346(41.8 \%)$ \\
True & $362(43.7 \%)$ \\
Wrong & $120(14.5 \%)$ \\
No idea & \\
\hline 6. In addition to N95, FDA sugg) & \\
\hline
\end{tabular}

6. In addition to N95, FDA suggested using of equivalent masks such as KN/KP95, PFF2, P2, DS/DL2, KOREAN SPECIAL $1^{\text {st }}$

True

Wrong

$456(55.1 \%$

No idea $284(34.3 \%)$

Additionally, at the end of the third part, there were two questions about the properties of $\mathrm{N} 95$ masks reported by ADA (24) (Table 2). Approximately $41.8 \%$ of the respondents answered correctly by stating that N95 masks have different sizes. In addition, the Food and Drug Administration recommended using masks equivalent to N95 quality during the COVID-19 period such as KN/KP95, PFF2, P2, DS/DL2, and Korean special 1st" (24). This information was identified by $55.1 \%$ of the respondents in this study.

The questions and answers regarding the participants' approach to dental procedures before and during the COVID-19 pandemic, which was carried out in the fourth part of the questionnaire, were shown in Table 3. The first question of this part was regarding the protective equipment used by dentists to prevent infections. Before the pandemic period, $94.7 \%$ of 
the participants stated that they used a surgical mask, while only $8 \%$ used an N95 mask. During the pandemic, the use of surgical masks decreased (80\%) and the use of N95 masks increased significantly (77.1\%). During the pandemic period, respondents' use of other protective equipment increased comparing to the period before COVID-19. Two-three times per week was the answer of $44 \%$ of the respondents when they asked about the frequency of lab coat washes before the pandemic while $62.1 \%$ of them stated that they used a disposable lab coat during the pandemic. In addition, the number of participants who washed their lab coats daily had increased during this period. The percent of dentists who did not leave the clinic with the clothes worn in the dental clinic before the pandemic was less than half (43.5\%), while this rate increased to approximately $96 \%$ during the pandemic period. Of the participants, $34.3 \%$ reported that the frequency of surgical mask changing in the pre-pandemic period was after each patient and $30 \%$ of them stated changing the mask after 2-3 patients. However, $63.5 \%$ of the dentists stated that they changed the surgical mask after each patient during this period. After the outbreak of the COVID-19 pandemic, the working hours of $79 \%$ of the respondents decreased comparing to the pre-pandemic time (Table 3).

Table 3. The dentists' approaches in the dental practices before and during COVID-19 pandemic.

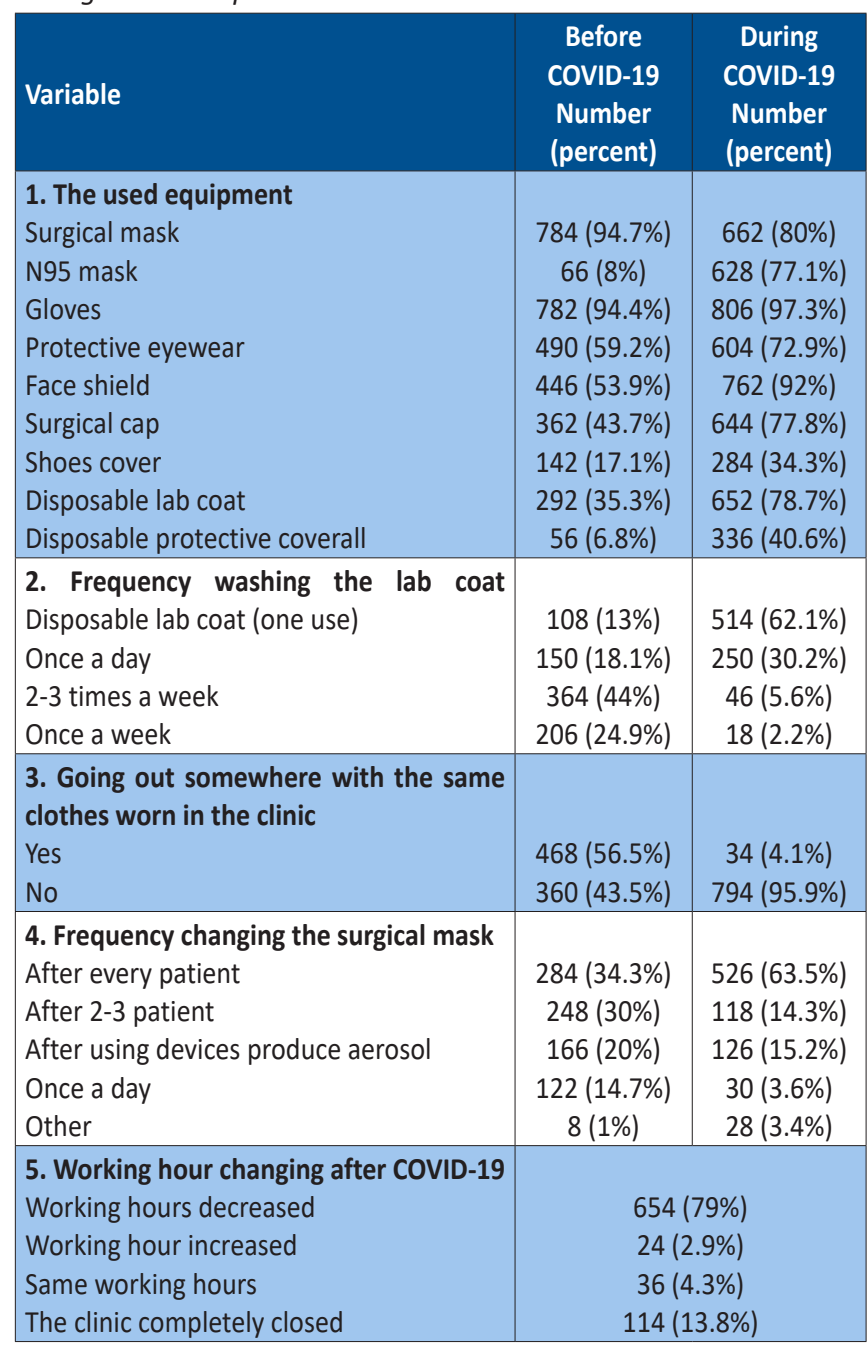

Table 4. The dentists' attitude toward dental procedures in preventing COVID-19.

\begin{tabular}{|l|c|}
\hline Variable & $\begin{array}{c}\text { Number } \\
\text { (percent) }\end{array}$ \\
\hline \begin{tabular}{l|} 
1. The dental procedures that you perform during \\
COVID-19 period
\end{tabular} \\
Only emergency cases & $662(80 \%)$ \\
Stopped all dental procedure during COVID-19 & $140(16.9 \%)$ \\
Restorative treatment & $72(8.7 \%)$ \\
Non-emergency endodontic treatment & $72(8.7 \%)$ \\
Non-emergency surgical treatment & $38(4.6 \%)$ \\
Prosthodontic treatment & $48(5.8 \%)$ \\
Periodontal treatment & $38(4.6 \%)$ \\
Orthodontic treatment & $52(6.3 \%)$ \\
\hline
\end{tabular}

\begin{tabular}{|l|c|}
\hline 2. How many times do you check the dental workers & \\
temperatures? & $460(55.6 \%)$ \\
Once a day & $202(24.4 \%)$ \\
2 times a day & $54(6.5 \%)$ \\
Once a week & $38(4.6 \%)$ \\
Every two weeks & $74(8.9 \%)$ \\
Other & \\
\hline 3. When do you change N95 mask if you use it? & $52(6.3 \%)$ \\
After every patient & $418(50.5 \%)$ \\
Once a day & $236(28.5 \%)$ \\
When becomes dirty, wet or deformed & $202(24.4 \%)$ \\
After using devices produce aerosol & \\
\hline
\end{tabular}

\section{Infection control measures in the dental clinic during} COVID-19 period

Taking the main complaint from the patients via telephone 334 (48.5\%) before accepting them in the clinic

Taking the patient's temperature and asking about any $562(81.7 \%)$ COVID-19 symptoms within 14 days

Provide the social distance $(2 \mathrm{~m})$ between patients in the $534(77.6 \%)$ waiting room

Using extraoral dental radiographs as an alternative to 404 (58.7\%) intraoral radiographs

Allow only the patient to enter the clinic without their $588(85.5 \%)$ relatives

Use of personal protective equipment by all dental staff $\quad 628(91.3 \%)$

Disinfecting the hands before and after the dental $612(89 \%)$

procedure with $60-95 \%$ alcohol, or washing them with

soap-water for at least 20 seconds

Make the patients to rinse their mouth with $1.5 \%$ hydrogen $372(54.1 \%)$ peroxide or $0.2 \%$ povidone before starting the treatment

Using absorbable sutures in surgical cases

$164(23.8 \%)$

$598(86.9 \%)$

$264(38.4 \%)$

Heat sterilization of the handpiece if used after every patient

Sufficient ventilation after every patient in the clinic

$568(82.6 \%)$

5. If the devises produce aerosol will be used, the following measures are applied

4-handed technique (with the nurse)

Using high vacuum suctions

Using rubber dam

I do nothing

Other

$298(36 \%)$

$430(51.9 \%)$

$136(16.4 \%)$

$188(22.7 \%)$

$108(13 \%)$

The summary of the last part's questions and responses, which was regarding the participants' attitudes towards dental procedures in order to prevent the risk of COVID-19 infection, was shown in Table 4. The majority of the participants $(80 \%)$ stated that they only applied 
treatment for emergency cases during the COVID-19 period, while $16.9 \%$ of them reported that they postponed all dental procedures. When the dentists were asked about the body temperature measuring of the workers in the clinic, $55.6 \%$ of them stated that they checked the body temperature once a day and $24.4 \%$ stated that they checked twice a day. In this survey study, only $24.4 \%$ of the participants stated that they changed $\mathrm{N} 95$ and equivalent masks after dental treatments that cause aerosol production and only $28.5 \%$ reported when they got wet, dirty, or deformed.

Seventy participants were excluded from the question regarding the measures in minimizing the risk of COVID-19 transmission in the dental clinic because they postponed accepting patients in this period and 668 dentists' responses were evaluated. The most followed measures by the dentists were, using protective equipment for all dental workers (91.3\%), disinfecting the hands before and after the dental procedure (89\%), and avoiding aerosol-generating devices (86.9\%). When using aerosol-generating devices, it was stated by $51.9 \%$ of the participants that the high vacuum suction was used as a precaution.

There was no association between the gender of the participants and the infection control measures $(P>$
0.05) except for the avoiding aerosol-generating devices measure $(P=000.1)$. Moreover, the participants' occupation (practitioners or academics) was significant associated only with the measures of maintaining the social distance between the patients $(P=0.03)$, using protective equipment for all dental workers $(P=0.032)$, rinse patients' mouths before starting the treatment $(P=0.001)$, and heat sterilizing the handpiece $(P<0.001)$.

In addition, significant associations were found between the dentists' specialty and the following measures: evaluating the patient's fever $(P=0.015)$, using extraoral dental radiographs $(P<0.001)$, using protective equipment for all dental workers $(P=0.001)$, rinse patients' mouths before starting the treatment $(P<0.001)$, avoiding aerosolgenerating devices $(P=0.001)$, and heat sterilizing the handpiece $(P<0.001)$.

Except for the using extraoral dental radiographs measure $(P=0.404)$, there was a significant association between the health sector and the infection control measures (Table 5). The associations between the experience years and the control measures were significant $(P<0.05)$ except for taking the patient's complaint by phone $(P=$ 0.152), measuring the patient's fever $(P=0.120)$, and using protective equipment for all dental workers $(P=$ 0.184) (Table 6).

Table 5. Comparison of the agree response of infection control measures in the dental clinic according to the health sector.

\begin{tabular}{|c|c|c|c|c|c|c|}
\hline Infection control measures & $\begin{array}{l}\text { Private } \\
\text { clinic } \\
\text { n (\%) }\end{array}$ & $\begin{array}{l}\text { Governmental } \\
\text { university } \\
\text { n (\%) }\end{array}$ & $\begin{array}{l}\text { Private } \\
\text { university } \\
\text { n (\%) }\end{array}$ & $\begin{array}{l}\text { Governmental } \\
\text { hospital } \\
\mathbf{n}(\%)\end{array}$ & $\begin{array}{l}\text { Private } \\
\text { hospital } \\
\text { n (\%) }\end{array}$ & $\begin{array}{c}\text { Chi-Square } \\
\text { Test }\end{array}$ \\
\hline Taking the main complaint of the patients first by phone & $148(83.1 \%)$ & $32(29.1 \%)$ & $24(52.2 \%)$ & $26(14.4 \%)$ & $104(59.8 \%)$ & $\begin{aligned} x^{2} & =240.363 ; \\
P & <0.001^{*}\end{aligned}$ \\
\hline $\begin{array}{l}\text { Measuring the patient's fever and asking if there were any } \\
\text { COVID-19 symptoms within } 14 \text { days }\end{array}$ & $136(76.4 \%)$ & 94 (85.5\%) & $44(95.7 \%)$ & $154(85.6 \%)$ & $134(77 \%)$ & $\begin{aligned} X^{2} & =25.103 \\
P & =0.005^{*}\end{aligned}$ \\
\hline $\begin{array}{l}\text { Maintaining the social distance between the patients in the } \\
\text { waiting room }\end{array}$ & $140(78.7 \%)$ & $86(78.2 \%)$ & $38(82.6 \%)$ & 124 (68.9\%) & $146(83.9 \%)$ & $\begin{array}{c}X^{2}=22.800 \\
P=0.013^{*}\end{array}$ \\
\hline $\begin{array}{l}\text { Using extraoral dental radiographs as an alternative to } \\
\text { intraoral radiographs }\end{array}$ & $98(55.1 \%)$ & 72 (65.5\%) & $22(47.8 \%)$ & $116(64.4 \%)$ & $96(55.2 \%)$ & $\begin{array}{l}x^{2}=4.011 \\
P=0.404\end{array}$ \\
\hline Accepting only the patients in the clinic without relatives & $146(82 \%)$ & $90(81.8 \%)$ & 44 (95.7\%) & $166(92.2 \%)$ & $142(81.6 \%)$ & $\begin{array}{l}x^{2}=28.696 \\
P=0.004\end{array}$ \\
\hline Using protective equipment for all dental workers & $160(89.9 \%)$ & $110(100 \%)$ & 44 (95.7\%) & $164(91.1 \%)$ & $150(86.2 \%)$ & $\begin{array}{c}X^{2}=40.218 \\
P=0.001^{*}\end{array}$ \\
\hline $\begin{array}{l}\text { Disinfecting the hands before and after the dental } \\
\text { procedure with } 60-95 \% \text { alcohol, or washing them with soap- } \\
\text { water for at least } 20 \text { seconds }\end{array}$ & $172(96.6 \%)$ & $94(85.5 \%)$ & $42(91.3 \%)$ & $142(78.9 \%)$ & $162(93.1 \%)$ & $\begin{array}{l}x^{2}=45.683 \\
P<0.001^{*}\end{array}$ \\
\hline $\begin{array}{l}\text { Rinse patients' mouths with } 1.5 \% \text { hydrogen peroxide or } \\
0.2 \% \text { povidone before starting the treatment }\end{array}$ & $122(68.5 \%)$ & $76(69.1 \%)$ & $24(52.2 \%)$ & $44(24.4 \%)$ & $106(60.9 \%)$ & $\begin{array}{c}x^{2}=97.758 \\
P<0.001^{*}\end{array}$ \\
\hline Using absorbable sutures in surgical cases & $56(31.5 \%)$ & $24(21.8 \%)$ & $16(34.8 \%)$ & $30(16.7 \%)$ & $38(21.8 \%)$ & $\begin{aligned} X^{2} & =21.697 \\
P & =0.006\end{aligned}$ \\
\hline Avoid using aerosol-generating devices as much as possible & $160(89.9 \%)$ & $98(89.1 \%)$ & $36(78.3 \%)$ & $170(94.4 \%)$ & $134(77 \%)$ & $\begin{aligned} x^{2} & =13.446 \\
P & =0.009^{*}\end{aligned}$ \\
\hline Heat sterilizing the handpiece (if used) after each patient & $100(56.2 \%)$ & $50(45.5 \%)$ & $16(34.8 \%)$ & $32(17.8 \%)$ & $66(37.9 \%)$ & $\begin{aligned} X^{2} & =63.756 \\
P & <0.001^{*}\end{aligned}$ \\
\hline Adequately ventilating the clinic after each patient. & $174(97.8 \%)$ & $86(78.2 \%)$ & $26(56.5 \%)$ & $144(80 \%)$ & $138(79.3 \%)$ & $\begin{aligned} x^{2}=46.687 \\
P<0.001^{*}\end{aligned}$ \\
\hline
\end{tabular}

"Indicates statistically significant. 
Table 6. Comparison of the agree response of infection control measures in the dental clinic according to the experience years in the profession.

\begin{tabular}{|c|c|c|c|c|c|c|}
\hline Infection control measures & $\begin{array}{l}1-5 \text { years } \\
n(\%)\end{array}$ & $\begin{array}{l}\text { 6-10 years } \\
n(\%)\end{array}$ & $\begin{array}{c}11-15 \text { years } \\
n(\%)\end{array}$ & $\begin{array}{l}16-20 \\
\text { years } \\
n(\%)\end{array}$ & $\begin{array}{l}\geq 21 \text { years } \\
n(\%)\end{array}$ & P values \\
\hline Taking the main complaint of the patients first by phone & $150(46.3 \%)$ & $96(45.7 \%)$ & $38(59.4 \%)$ & $16(50 \%)$ & $34(58.6 \%)$ & $x^{2}=5.709 ; P=0.152$ \\
\hline $\begin{array}{l}\text { Measuring the patient's fever and asking if there were any } \\
\text { COVID-19 symptoms within } 14 \text { days }\end{array}$ & $258(79.6 \%)$ & $178(84.8 \%)$ & $56(87.5 \%)$ & $22(68.8 \%)$ & $48(82.8 \%)$ & $x^{2}=3.249 ; P=0.120$ \\
\hline $\begin{array}{l}\text { Maintaining the social distance between the patients in } \\
\text { the waiting room }\end{array}$ & $260(80.2 \%)$ & $158(75.2 \%)$ & $54(84.4 \%)$ & $26(81.3 \%)$ & $36(62.1 \%)$ & $x^{2}=11.686 ; P=0.018^{*}$ \\
\hline $\begin{array}{l}\text { Using extraoral dental radiographs as an alternative to } \\
\text { intraoral radiographs }\end{array}$ & $152(46.9 \%)$ & $140(66.7 \%)$ & $52(81.3 \%)$ & $24(75 \%)$ & $36(62.1 \%)$ & $x^{2}=51.604 ; P<0.001^{*}$ \\
\hline Accepting only the patients in the clinic without relatives & $280(86.4 \%)$ & $190(90.5 \%)$ & $46(71.9 \%)$ & $30(93.8 \%)$ & $42(72.4 \%)$ & $x^{2}=22.070 ; P<0.001^{*}$ \\
\hline Using protective equipment for all dental workers & $290(89.5 \%)$ & $200(95.2 \%)$ & $58(90.6 \%)$ & $28(87.5 \%)$ & $52(89.7 \%)$ & $x^{2}=9.427 ; P=0.184$ \\
\hline $\begin{array}{l}\text { Disinfecting the hands before and after the dental } \\
\text { procedure with } 60-95 \% \text { alcohol, or washing them with } \\
\text { soap-water for at least } 20 \text { seconds }\end{array}$ & $278(85.8 \%)$ & $186(88.6 \%)$ & $62(96.9 \%)$ & $32(100 \%)$ & $54(93.1 \%)$ & $x^{2}=27.667 ; P=0.015^{*}$ \\
\hline $\begin{array}{l}\text { Rinse patients' mouths with } 1.5 \% \text { hydrogen peroxide or } \\
0.2 \% \text { povidone before starting the treatment }\end{array}$ & $140(43.2 \%)$ & $114(54.3 \%)$ & $50(78.1 \%)$ & $22(68.8 \%)$ & $46(79.3 \%)$ & $x^{2}=59.780 ; P<0.001^{*}$ \\
\hline Using absorbable sutures in surgical cases & $70(21.6 \%)$ & $42(20 \%)$ & $22(34.4 \%)$ & $8(25 \%)$ & $22(37.9 \%)$ & $x^{2}=13.256 ; P=0.012$ \\
\hline $\begin{array}{l}\text { Avoid using aerosol-generating devices as much as } \\
\text { possible }\end{array}$ & $268(82.7 \%)$ & $198(94.3 \%)$ & $58(90.6 \%)$ & $28(87.5 \%)$ & $46(79.3 \%)$ & $x^{2}=23.615 ; P=0.001^{*}$ \\
\hline Heat sterilizing the handpiece (if used) after each patient & $92(28.4 \%)$ & $84(40 \%)$ & $38(59.4 \%)$ & $12(37.5 \%)$ & $38(65.5 \%)$ & $x^{2}=51.804 ; P<0.001^{*}$ \\
\hline Adequately ventilating the clinic after each patient. & $260(80.2 \%)$ & $166(79 \%)$ & $62(96.9 \%)$ & $26(81.3 \%)$ & $54(93.1 \%)$ & $x^{2}=12.296 ; P=0.015^{*}$ \\
\hline
\end{tabular}

* Indicates statistically significant.

\section{DISCUSSION}

The epidemic of COVID-19, which has been spread to 216 countries, areas or territories (9), is a global matter of debate throughout the world, especially among healthcare staff and patients. Many studies reported the risk of spreading infection among healthcare workers $(11,12)$. They are at risk to be infected by SARS-CoV-2 and to be carriers of this infection due to reasons such as being in close contact with patients, being exposed to saliva, blood and other body fluids, and using sharp hand tools $(1,25)$. It was stated that dentists are the occupational group most exposed to the risk of being affected by the new type of coronavirus disease (26). This survey study investigated the level of awareness and approaches of dentists in Turkey regarding COVID-19 and found out the control measures followed in the dental practice to prevent infections before and during the pandemic period.

The number of dentists under 30 years of age and 30 years and over who participated in this study was almost equal in which the majority of the participants were in the 25-33 age group. This could be attributed to the tendency of the younger age groups to participate in online surveys on social media platforms. More than half of the dentists (58.9\%) in this survey study were female. Şirinoğlu Çapan et al. (27) reported that many female students preferred studying dentistry because of their working conditions and hours. However, these results were similar to previous COVID-19 studies (28-30), while they were inconsistent with other studies (31-33).

In the present survey, most of the participants were general practitioners, while the academicians formed a rate of $12.8 \%$.
These results were in agreement with the results of Kamate et al. (34) but inconsistent with Sezgin and Şirinoğlu Çapan (29). Dentists in Turkey were employed to check and follow-up the COVID-19 infected patients in their home which made the dentists in the first line of the struggle against this virus in this critical period. The participation rate of this group of dentists was $8.9 \%$ which could be due to their intense and stressful working pace.

It is extremely important to have reliable and informative resources enough to enable physicians to evaluate the situations that they face regarding COVID-19 in order to take the spread of COVID-19 under control. For dental professionals, the most accurate and reliable resources are the websites of official organizations. This survey study was prepared and designed according to the guidelines and data of the relative literature, WHO (19), CDC (20), and ADA (21).

In this survey study, the participants were asked about the transmission ways of COVID-19 and the results showed that more than $92 \%$ of dentists were aware of the correct answers. These results were similar to the results of previous studies regarding the transmission ways. ${ }^{28,29,34}$ The incubation period of SARS-CoV-2 was 2-14 days which was confirmed by the CDC. ${ }^{22}$ In the present study, approximately $73.2 \%$ of the respondents correctly answered the question regarding the incubation time of this infection. It is important to know the incubation time especially because of its role in determining the safe period for the treatment of suspicious patients (35). Nonetheless, Turkish dentists in this study could identify the main symptoms of COVID-19, which helped the dentists to recognize the threat and take the necessary actions and the management and control of the spread of this disease 
$(28,35)$. In addition, it is essential to take control measures by the dentists with their patients at all time because some patients could be infected even when the disease progresses asymptomatically (36).

It was believed that the high awareness level of the participants regarding SARS-CoV-2 disease in this study was due to the fact that Turkey was affected by this virus later comparing to other countries, and the great efforts of the Ministry of Health and dental associations in informing the dentists quickly about it.

Coronavirus can survive on nonliving surfaces such as metal, glass, or plastic for up to 9 days, which increases the risk of infection, and could be effectively inactivated using surface disinfection products containing $0.5 \%$ hydrogen peroxide, $62-71 \%$ ethanol or $0.1 \%$ sodium hypochlorite for 1 minute (37). Aerosol transmission is also possible (36). Doremalen et al. (38) reported that the virus can survive and be detected in aerosol for up to 3 hours after procedures that lead to aerosol formation. If dental clinic workers were not wearing appropriate personal protective equipment, these aerosols could potentially be inhaled. The results of this study showed the increased use of personal protective equipment by the dentists during the SARS-CoV-2 pandemic time.

Since the incubation period of this disease is 2-14 days, it is not possible to differentiate asymptomatic infected patients. Thus, the ADA (21) recommended that the treatments in dental clinics should be limited to emergency cases during the COVID-19 pandemic. In the present study, most of the participants (80\%) stated that they performed dental procedures only for emergency cases, while $16.9 \%$ stopped performing all dental procedures during this period. Similarly, Izzeti et al. (32) stated in their cross-sectional study, which was carried out in Italy, that $75.5 \%$ of the respondents performed only the dental procedures for emergency cases, while Gambhir et al. (31) reported that $8.5 \%$ of participants in India answered the same response.

$\mathrm{CDC}(20)$ recommended measuring the temperature of the workers in dental clinics twice a day. The dentists in this survey checked the body temperatures of the clinic workers once and twice a day with the rates of $55.6 \%$ and $24.4 \%$, respectively. ADA (24) reported that N95 and equivalent masks that reduce the exposure to particles, including small aerosols particle and large droplets (non-oil aerosols), should be discarded after dental treatments that produce aerosols. In addition, it was stated that the wet, dirty or deformed masks should also be discarded (24). The results of this survey showed that $24.4 \%$ of the respondents discarding the mask after procedures that caused aerosol generation and $28.5 \%$ after becoming wet, dirty, or deformed. This could be due to the limited distribution of these masks to dentists and their high cost across the country.

Considering the working conditions of dentists, they should always use personal protective equipment in dental clinics. Also, dentists are at high risk of COVID-19 infection and they need to take additional precautions during the COVID-19 outbreak. Egger et al. (39) demonstrated that both SARS and MERS viruses were highly sensitive to povidone-iodine mouthwash. During the COVID-19 pandemic period, it was recommended that the patients wash their mouths with $0.2 \%$ povidone-iodine or $1.5 \%$ hydrogen peroxide before dental treatment to reduce the amount of coronavirus in saliva (21). However, only $54.1 \%$ of the dentists in this study stated that they rinsed the patients' mouths with hydrogen peroxide or povidone before dental treatment. In a recent study (40) involving participants from different countries around the world, only $24 \%$ of them stated that they asked patients to rinse their mouths with antimicrobial mouthwash before dental treatment.

In order to reduce the exposure to possible infectious agents during dental procedures that cause aerosol production, ADA (21) recommended some measures such as the use of a 4-handed technique, high-volume saliva ejectors, and a rubber dam. The present study showed that $51.9 \%$ of the participants stated using high-volume saliva ejectors and $36 \%$ of them used 4 -handed technique.

In this study, using absorbable sutures in surgical cases (23.8\%) constituted the least percentage among the infection control measures taken in dental clinics. The reason for this situation may be related to the avoidance of non-urgent surgical interventions during the pandemic period. The measure of first learning about the patient's main complaint by phone in the government hospital (14.4\%) and government university (29.1\%) sectors were less than the other health sectors. This situation may be related to the fact that the government health sectors continued to work for emergency treatments without an appointment during the pandemic period. More than $95 \%$ of the dentists working in private clinics stated that they ventilate the clinic sufficiently after each patient, which was the highest percentage compared to the other health sectors. This situation may be associated with the presence of a single unit in private clinics.

According to the results of this study, the use of protective equipment and the disinfection of hands were observed over $85 \%$ in all experience years groups. However, Putrino et al. [41] stated that the aforementioned control measures were applied by almost $26 \%$ of the participants in Italy during the COVID-19 process.

It should be noted that dentists who work during the pandemic are at high risk of COVID-19 infection. Therefore, every patient should be considered potentially infected with the virus, and current infection control protocols should be applied during all dental treatments. For this purpose, all dentists should follow the latest information and read reliable and up-to-date resources.

One of the limitations of this study was that the sample size was smaller than the expected. This could be because of data was collected in a short time to keep the study up to date. Since the dentists in this study participated using email and social network platforms, the study was subject to selection bias and sampling error. Another limitation was that younger 
dentists constituted the majority of participants who applied in the study. The reason for this situation could be related to the spread of the survey on the internet for a short time due to the pandemic. In addition, it was not determined whether the dentists participating in the study were infected with COVID-19 or not, and therefore it was not clear whether there was a difference between dentists' taking precautions against COVID-19 or not. The prevalence of dentists in Turkey infected with COVID-19 is essential to be investigated in future studies.

\section{CONCLUSION}

Within the limitations of this study, the level of knowledge about the ways of transmission and symptoms regarding COVID-19 is a quite high among dentists in Turkey. Beside the rate of using personal protective equipment during dental treatment was high, it is important to follow and apply the current infection control measures which published by official institutions to ensure effective infection control. In order to obtain more comprehensive results more studies are needed with larger sample sizes across the country and the world in the future.

\section{REFERENCES}

[1] Ather A, Patel B, Ruparel NB, Diogenes A, Hargreaves KM. Coronavirus Disease 19 (COVID-19): Implications for Clinical Dental Care. J Endod 2020;46(5):584-595.

[2] World Health Organization. Novel Coronavirus(2019nCoV) Situation Report - 11, 2020. (cited 2020 May 26). Available from: https://www.who.int/docs/default-source/ coronaviruse/situation-reports/20200131-sitrep-11-ncov. pdf?sfvrsn=de7c0f7_4.

[3] Republic of Turkey Ministry of Health. COVID-19 Information Page General Coronavirus Table, 2020. (cited 2020 Sep 20). Available from: https://covid19.saglik.gov.tr/EN-69532/ general-coronavirus-table.html.

[4] World Health Organization. WHO Director-General's opening remarks at the media briefing on COVID-19 - 11 March 2020. (cited 2020 May 26). Available from: https://www.who.int/dg/ speeches/detail/who-director-general-s-opening-remarks-atthe-media-briefing-on-covid-19-11-march-2020.

[5] Hasöksüz M, Kiliç S, Saraç F. Coronaviruses and sars-cov-2. Turk J Med Sci 2020;50:549-556.

[6] Rabaan AA, Al-Ahmed SH, Haque S, Sah R, Tiwari R, Malik YS, Dhama K, Yatoo MI, Bonilla-Aldana DK, Rodriguez-Morales AJ. SARS-CoV-2, SARS-CoV, and MERS-COV: A comparative overview. Infez Med 2020;28(2):174-184.

[7] Coronaviridae Study Group of the International Committee on Taxonomy of Viruses. The species Severe acute respiratory syndrome-related coronavirus: classifying 2019-nCoV and naming it SARS-CoV-2. Nat Microbiol 2020;5(4):536-544.

[8] Jiang $X$, Rayner S, Luo MH. Does SARS-CoV-2 has a longer incubation period than SARS and MERS? J Med Virol 2020;92(5):476-478.

[9] World Health Organization. Coronavirus disease (COVID-19) pandemic, 2020. (cited 2020 Sep 12). Available from: https:// www.who.int/emergencies/diseases/novel-coronavirus-2019.
[10] World Health Organization. WHO Coronavirus Disease (COVID-19) Dashboard, 2020. (cited 2020 Sep 12). Available from: https://covid19.who.int/region/euro/country/tr.

[11] Wang D, Hu B, Hu C, Zhu F, Liu X, Zhang J, Wang B, Xiang $\mathrm{H}$, Cheng Z, Xiong Y, Zhao Y, Li Y, Wang X, Peng Z. Clinical Characteristics of 138 Hospitalized Patients with 2019 Novel Coronavirus-Infected Pneumonia in Wuhan, China. JAMA 2020;323(11):1061-1069.

[12] Ran L, Chen X, Wang Y, Wu W, Zhang L, Tan X. Risk Factors of Healthcare Workers with Corona Virus Disease 2019: A Retrospective Cohort Study in a Designated Hospital of Wuhan in China. Clin Infect Dis. 2020;ciaa287. doi: 10.1093/ $\mathrm{cid} / \mathrm{ciaa2} 287$.

[13] Ağalar C, Öztürk Engin D. Protective measures for covid-19 for healthcare providers and laboratory personnel. Turk J Med Sci 2020;50:578-584.

[14] To KK, Tsang OT, Yip CC, Chan KH, Wu TC, Chan JM, Leung WS, Chik TS, Choi CY, Kandamby DH, Lung DC, Tam AR, Poon RW, Fung AY, Hung IF, Cheng VC, Chan JF, Yuen KY. Consistent detection of 2019 novel coronavirus in saliva. Clin Infect Dis 2020. doi: $10.1093 /$ cid/ciaa149

[15] Pascarella G, Strumia A, Piliego C, Bruno F, Del Buono R, Costa F, Scarlata S, Agrò FE. COVID-19 diagnosis and management: a comprehensive review. J Intern Med 2020;288(2):192-206.

[16] Centers for Disease Control and Prevention. How COVID-19 Spreads?, 2020. (cited 2020 May 31). Available from: https:// www.cdc.gov/coronavirus/2019-ncov/prevent-getting-sick/ how-covid-spreads.html.

[17] Ge ZY, Yang LM, Xia JJ, Fu XH, Zhang YZ. Possible aerosol transmission of COVID-19 and special precautions in dentistry. J Zhejiang Univ Sci B 2020;21(5):361-368.

[18] Peng X, Xu X, Li Y, Cheng L, Zhou X, Ren B. Transmission routes of 2019-nCoV and controls in dental practice. Int J Oral Sci. 2020;12(1):9.

[19] World Health Organization. Infection prevention and control during health care when COVID-19 is suspected, 2020. (cited 2020 May 31). Available from: https://www.who.int/ publications-detail/infection-prevention-and-control-duringhealth-care-when-novel-coronavirus-(ncov)-infection-issuspected-20200125.

[20] Centers for Disease Control and Prevention. Guidance for Dental Settings, 2020. (cited 2020 May 31). Available from: https://www.cdc.gov/coronavirus/2019-ncov/hcp/dentalsettings.html.

[21] American Dental Association. ADA Interim Guidance for Minimizing Risk of COVID-19 Transmission, 2020. (cited 2020 May 31). Available from: https://www.ada.org/media/CPS/ Files/COVID/ADA_COVID_Int_Guidance_Treat_Pts.pdf.

[22] Centers for Disease Control and Prevention. Symptoms of Coronavirus, 2020. (cited 2020 Aug 10). Available from: https://www.cdc.gov/coronavirus/2019-ncov/symptomstesting/symptoms.html.

[23] Centers for Disease Control and Prevention. People at Increased Risk, 2020. (cited 2020 Aug 10). Available from: https://www.cdc.gov/coronavirus/2019-ncov/need-extraprecautions/index.html.

[24] American Dental Association. Interim Mask and Face Shield Guidelines, 2020. (cited 2020 May 31). Available from: https:// success.ada.org/ /media/CPS/Files/COVID/ADA_Interim_ Mask_and_Face_Shield_Guidelines.pdf. 
[25] Spagnuolo G, De Vito D, Rengo S, Tatullo M. COVID-19 outbreak: An overview on dentistry. Int J Environ Res Public Health 2020;17(6):2094.

[26] Gamio L. The Workers Who Face the Greatest Coronavirus Risk, 2020. (cited 2020 March 15). Available from: https://www. nytimes.com/interactive/2020/03/15/business/economy/ coronavirus-worker - risk.html

[27] Şirinoglu Çapan B, Akyüz S, Bahçeçik AN, Yarat A, Girgin F. Factors influencing career choices of dental students in a state university in Turkey. Clin Exp Health Sci 2018;8(4):228-236.

[28] Khader Y, Al Nsour M, Al-Batayneh OB, Saadeh R, Bashier H, Alfaqih M, Al-Azzam S, AlShurman BA. Dentists' Awareness, Perception, and Attitude Regarding COVID-19 and Infection Control: Cross-Sectional Study Among Jordanian Dentists. JMIR Public Health Surveill 2020;6(2):e18798. doi: 10.2196/18798.

[29] Sezgin GP, Şirinoğlu Çapan B. Assessment of dentists' awareness and knowledge levels on the Novel Coronavirus (COVID-19). Braz Oral Res 2020;34:e112. doi: 10.1590/18073107bor-2020.vol34.0112.

[30] Teja KV, Vasundhara KA, Sriram G. Knowledge, awareness, and practice of dentists in preventing-novel corona virus (COVID-19) transmission-a questionnaire based crosssectional survey. Braz Dent Sci 2020;23(2):1-9.

[31] Gambhir RS, Dhaliwal JS, Aggarwal A, Anand S. Covid-19: a survey on knowledge, awareness and hygiene practices among dental health professionals in an Indian scenario. Rocz Panstw Zakl Hig 2020;71(2):223-229.

[32] Izzetti R, Gennai S, Nisi M, Barone A, Giuca MR, Gabriele M, Graziani F. A perspective on dental activity during COVID-19: the Italian survey. Oral Dis 2020. doi: 10.1111/odi.13606.

[33] Ahuja A, Razi MA, Qamar S. Assesment of knowledge and awareness regarding novel coronavirus (COVID-19) among dental professionals of Hazaribag District, Jharkhand, India. IP Int J Periodontol Implantol 2020;5(2):78-86.
[34] Kamate SK, Sharma S, Thakar S, Srivastava D, Sengupta K, Hadi AJ, Chaudhary A, Joshi R, Dhanker K. Assessing knowledge, attitudes and practices of dental practitioners regarding the covid-19 pandemic: A multinational study. Dent Med Probl 2020;57(1):11-17.

[35] Gaffar BO, El Tantawi M, Al-Ansari AA, AlAgl AS, Farooqi FA, Almas KM. Knowledge and practices of dentists regarding MERS-CoV: A cross-sectional survey in Saudi Arabia. Saudi Med J 2019;40(7):714-720.

[36] World Health Organization. Q\&A: How is COVID-19transmitted? 2020 (cited 2020 Sep 13) Available from: https://www.who. int/emergencies/diseases/novel-coronavirus-2019/questionand-answers-hub/q-a-detail/q-a-how-is-covid-19-transmitted.

[37] Kampf G, Todt D, Pfaender S, Steinmann E. Persistence of coronaviruses on inanimate surfaces and their inactivation with biocidal agents. J Hosp Infect 2020;104(3):246-251.

[38] van Doremalen N, Bushmaker T, Morris DH, Holbrook MG, Gamble A, Williamson BN, Tamin A, Harcourt JL, Thornburg NJ, Gerber SI, Lloyd-Smith JO, de Wit E, Munster VJ. Aerosol and surface stability of SARS-CoV-2 as compared with SARS-CoV-1. N Engl J Med 2020;382(16):1564-1567.

[39] Eggers $M$, Koburger-Janssen T, Eickmann M, Zorn J. In Vitro Bactericidal and Virucidal Efficacy of Povidone-lodine Gargle/ Mouthwash Against Respiratory and Oral Tract Pathogens. Infect Dis Ther 2018;7(2):249-259.

[40] Ahmed MA, Jouhar R, Ahmed N, Adnan S, Aftab M, Zafar MS, Khurshid Z. Fear and practice modifications among dentists to combat novel coronavirus disease (COVID-19) outbreak. Int J Environ Res Public Health 2020;17(8):2821.

[41] Putrino A, Raso M, Magazzino C, Galluccio G. Coronavirus (COVID-19) in Italy: knowledge, management of patients and clinical experience of Italian dentists during the spread of contagion. BMC Oral Health. 2020;20(1):200. 